\title{
Morfometria de sementes leguminosas produzidas em diferentes espaçamentos
}

\section{Morphometry of leguminous seeds produced in different spacing}

\author{
Shirley Santos Monteiro ${ }^{1 *}$; Fillipe Silveira Marini ${ }^{2}$; Dualyson da Silva Santos ${ }^{3}$; Emmanuel Moreira \\ Pereira ; Andreia Vasconcellos ${ }^{5}$
}

${ }^{1}$ Mestre em Tecnologia Agroalimentar, Universidade Federal da Paraíba, Centro de Ciências Humanas Sociais e Agrárias, Bananeiras, Paraíba, shirley_pinto_monteiro@hotmail.com; ²Docente/Pesquisador do Departamento de Geociências, Universidade Federal da Paraíba, João Pessoa, Paraíba, fsmarini@yahoo.com.br; ${ }^{3}$ Bacharel em Agroecologia, Universidade Federal da Paraíba. Centros de Ciências Humanas, Sociais e Agrárias, Bananeiras Paraíba, dualyson@hotmail.com; ${ }^{4}$ Doutorando em Agronomia, Universidade Estadual Paulista, Faculdade de Ciências Agrárias e Veterinárias, Jaboticabal, emmanuel16mop@hotmail.com; ${ }^{5}$ Doutoranda em Extensão Rural, Universidade Federal de Santa Maria, Santa Maria, Rio Grande do Sul, dreagroeco@gmail.com.

\section{N O T A}

Recebido: 30/09/2018

Aprovado: 29/11/2018

\section{Palavras-chave:}

Dolichos lablab L.

Mucuna aterrima

Canavalia ensiformis D. C.

Key words:

Dolichos lablab L

Mucuna aterrima

Canavalia ensiformis D. C.

\section{R E S U M O}

A produção de sementes de leguminosa pode ser uma estratégia para aumentar a renda dos agricultores familiares, assim como a melhoria das características do solo. O objetivo deste trabalho foi avaliar as características morfométricas das sementes de espécies leguminosas produzidas em diferentes espaçamentos. O experimento foi conduzido na Universidade Federal da Paraíba, Campus III, Bananeiras, Paraíba. O delineamento utilizado foi em blocos casualizados no esquema fatorial 3 x 3, sendo três espécies de leguminosas (mucuna preta, feijão de porco e lablab, ) e três espaçamentos $(0,50 \times 0,50 ; 0,50 \times 0,75$ e $0,50 \times 1,0$ $\mathrm{m})$ com três repetições. Avaliou-se as características físicas: comprimento e largura de vagem, comprimento e largura de semente, peso da vagem com semente, peso da vagem sem semente, peso da semente, número de semente por vagem, produtividade, peso total da vagem, peso total da semente e peso de 100 semente. A leguminosa Feijão de Porco teve maior acréscimo no desempenho morfométrico, seguido da Mucuna Preta e Lablab. Os espaçamentos não apresentaram influência na morfometria das sementes das leguminosas.

A B S T R A C T
The production of legume seeds can be a strategy to increase the income of family farmers,
as well as the improvement of soil characteristics. The objective of this work was to
evaluate the morphometric characteristics of the seeds of legume species produced at
different spacings. The experiment was conducted at the Federal University of Paraíba,
Campus III, Bananeiras, Paraíba. The experimental design was a randomized complete
block design in the $3 \times 3$ factorial scheme, three legume species (black mucuna, pork bean
and lablab) and three spacings ( 0.50 x $0.50,0.50 \times 0.75$ e 0.50 x 1.0 m) with three
replicates. It was evaluated the physical characteristics: pod length and width, seed length
and width, seed pod weight, seedless pod weight, seed weight, seed number per pod, yield,
total pod weight, total weight of the seed and weight of 100 seed. The legume Bean of Pork
had greater increase in morphometric performance, followed by Mucuna Preta and Lablab.
The spacing did not influence the Morphometry of leguminous seeds.

\section{INTRODUÇÃO}

A família botânica Fabaceae compõe um dos principais e mais importantes grupos de plantas. Esta família é constituída por 751 gêneros e cerca de 19 mil espécies, estando dividida em três subfamílias - Caesalpinioideae, Mimosoideae e Faboideae (HOWIESON et al., 2008; LIMA et al., 2017).

As leguminosas estão distribuídas mundialmente nos trópicos úmidos, nas regiões temperadas, nas zonas áridas, na vegetação de altitude ou montanhosa, nas savanas e nas terras baixas. O Brasil é particularmente rico em leguminosas e estima-se que $15 \%$ das espécies da família crescem nos nossos diferentes ecossistemas. Algumas leguminosas têm sido muito aproveitadas na produção agrícola e são plantas preferenciais para adubação verde pela alta concentração de nitrogênio de sua parte aérea, especialmente das folhas (SOUZA, 2012) e na disponibilidade alimentar, principalmente nos países mais pobres, dentre as diversas espécies, destacam-se a mucuna preta, feijão de porco e a lablab.

\section{Revista Verde}

ISSN 1981-8203

Pombal, Paraíba, Brasil v. 14, n.1, jan.-mar, p.146-149, 2019

doi: $10.18378 /$ rvads.v14i1.5881 
A mucuna preta (Mucuna aterrima) é uma planta anual, herbácea, rasteira, com ramos trepadores vigorosos e bem desenvolvidos (TADESCO, 2009). É uma planta de crescimento rápido possui grande quantidade de massa verde para cobertura do solo, muito utilizada na agricultura brasileira. A alta produtividade aliada ao baixo custo de produção tem feito da mucuna uma das principais culturas utilizadas na adubação verde no Brasil (BUENO et al., 2007). O seu ciclo de plantio ao pleno florescimento é de 140 a 180 dias. Ao final do ciclo a mucuna preta seca formando um manto sobre o solo de alguns centímetros. Esta camada funciona como uma excelente cobertura morta (FORMENTINI et al., 2008).

O feijão de porco (Canavalia ensiformis D. C.) é uma leguminosa anual, rústica e de hábito herbáceo, originária da América Tropical. É cultivada em regiões tropicais e equatoriais. É resistente às altas temperaturas e à seca. Seu uso é recomendado para adubação verde, sendo cortada e incorporada ao solo no início da floração, aproximadamente 120 dias após o plantio (RODRIGUES et al., 2004). Possui efeito alelopático sendo muito usado no controle de tiririca (Cyperus rotundus L.) (FORMENTINI et al., 2008; BARRETO et al., 2006).

O lablab (Dolichos lablab L.) é uma leguminosa anual ou bianual originária da África, de hábito de crescimento trepador cujo ciclo do plantio ao pleno florescimento é de 120 a 150 dias. Desenvolve-se, melhor, em solos bem drenados e férteis, porém é empregado, com êxito, como adubação verde, para restauração de terras pobres; sendo, também, utilizada como forragem nos meses de inverno (FORMENTINI et al., 2008).

A posse e o domínio das sementes representaram a mudança do ser humano, nos seus primórdios, de coletor e caçador para agricultor sedentário. Neste processo o ser humano foi dominando técnicas de domesticação de espécies vegetais, selecionando e criando cultivares mais adaptadas ao seu ambiente. O processo de modernização da agricultura causou mudança significativa na prática dos agricultores, de selecionar plantas e conservar sementes crioulas. A recuperação deste patrimônio cultural diz respeito à própria preservação da biodiversidade existente no planeta e a coevolução de sistemas agrícolas (BEVILAQUA; ANTUNES, 2008).

A semente é vida, é base de alimento, de multiplicação, de crescimento, de sobrevivência, é o elemento básico da agricultura como estratégia social. Na vida camponesa a posse das sementes próprias representa autonomia, liberdade, poder popular, independência e autossuficiência (GUTIÉRREZ, 2003). A realidade tem mostrado que os pequenos agricultores têm realizado um papel que vai além da agricultura.

Baseando-se em uma perspectiva agroecológica o uso de variedades crioulas é um fator condicionante para um manejo dos agroecossistemas saudáveis e sustentáveis, pois essa estratégia viabiliza o emprego de genótipos localmente adaptados, que são capazes de converter recursos abióticos disponíveis nos agroecossistemas em biomassa de interesse econômico (PETERSEN et al., 2013).

A tentativa de conhecer e entender os fatores de produção das sementes de leguminosas, assim como a sua adaptação em alguns municípios com características de semiaridez na Paraíba. Nos dias atuais a produção de sementes de leguminosas passa por um período de estudos, de multiplicação e de divulgação após de ter chegado quase a sua extinção com o surgimento das sementes geneticamente modificadas.

Diante da ausência de informações sobre o desenvolvimento produtivo de espécies de leguminosas, o objetivo deste trabalho foi avaliar as características morfométricas das vagens de sementes de mucuna preta, feijão de porco e lablab produzidas com distintos espaçamentos.

\section{MATERIAL E MÉTODOS}

O experimento foi conduzido no Centro de Ciências Humanas, Sociais e Agrárias (CCHSA) pertencente a Universidade Federal da Paraíba, no município de Bananeiras-PB (6²6'S; 35³8'W; $617 \mathrm{~m}$ de altitude). O clima da região é classificado como tipo As (tropical chuvoso), quente e úmido, conforme Köppen (Santos et al., 2010). O solo da área experimental foi classificado como Latossolo Vermelho Amarelo distrófico, de textura franco arenosa a franco argilosa, cujas características químicas antes da instalação do experimento, na camada de 0 - $20 \mathrm{~m}$ de profundidade foram $\mathrm{pH}=5,34 ; \mathrm{MO}=5,34 \mathrm{~g} \mathrm{~kg}^{-1} ; \mathrm{P}$ Mehlich $=52,24 \mathrm{mg} \mathrm{dm}-3 ; \mathrm{Na}=0,09$ cmolc dm $-3 ; \mathrm{Al}=0,15$ cmolc $\mathrm{dm}-3 ; \mathrm{H}+\mathrm{Al}=2,31$ cmolc $\mathrm{dm}-3 ; \mathrm{K}=12,0 \mathrm{cmolc} \mathrm{dm}^{-3} ; \mathrm{Ca}=$ $1,55 \mathrm{cmolc} \mathrm{dm}^{-3} ; \mathrm{Mg}=3,49$ cmolc dm-3; $\mathrm{SB}=5,8$ cmolc dm3; $\mathrm{CTC}=4,12$ cmolc dm-3; V = 60,2\%

Foram selecionadas sementes das leguminosas: mucuna preta (MP), feijão de porco (FP) e lablab (LL), adquiridas do banco de germoplasma do Laboratório de Tecnologia de Sementes do CCHSA. Os experimentos foram desenvolvidos entre maio a outubro de 2014 e o índice médio da pluviosidade durante o período foi de $129,32 \mathrm{~mm}$ no ano agrícola de 2014, segundo a Agência Executiva de Gestão das Águas do Estado da Paraíba (AESA).

$\mathrm{O}$ delineamento experimental utilizado foi $\mathrm{o}$ Delineamento em Blocos Casualizados (DBC) no esquema fatorial $3 \times 3$, onde foram utilizadas três espécies de leguminosas (mucuna preta, feijão de porco e lablab) produzidas em três espaçamentos $(0,50 \times 0,50 ; 0,50 \times 0,75 \mathrm{e}$ $0,50 \times 1,0 \mathrm{~m}$ ), em três repetições. As parcelas experimentais foram de $3 \times 4 \mathrm{~m}$, sendo utilizada como parcela útil as linhas centrais de cada parcela.

O plantio foi realizado manualmente com duas sementes por cova e após a germinação realizou-se o debate deixandose uma planta por cova, o experimento foi conduzido de forma de sequeiro, utilizando os espaçamentos de 0,50 x 0,50 (E1), 0,50 x 0,75 (E2) e 0,50 x 1,0 m (E3). Os tratos culturais foram realizados de acordo com as necessidades das culturas. Foi realizado o controle das saúvas com a utilização de defensivos naturais (extrato de nim (Azadirachta indica A. Juss), calda de tabaco (Nicotiana tabacum L.) e manipuera).

As parcelas experimentais foram compostas por 63 plantas $(0,50 \times 0,50), 24$ plantas $(0,50 \times 0,75)$ e 20 plantas $(0,50 \times 1,0)$ por espaçamentos, sendo considerada a parcela útil a linha composta por 06 plantas centrais. Nas áreas experimentais foi realizada o preparo do solo com uma aração e gradagem sem adubação ou calagem.

As colheitas das leguminosas deram-se aos 151 e 169 dias após a semeadura. As avaliações foram realizadas no Laboratório de Análise de Sementes.

As análises morfométricas avaliadas foram: Comprimento da vagem (CV), largura da vagem (LV), 
comprimento da semente (CS), largura da semente (LS), peso da vagem com semente (PVcS), peso da vagem sem semente (PVsS), peso da semente (PS), número de semente por vagem $(\mathrm{NSpV})$, peso total da produção (PTP), peso total das vagens (PTV), peso total das sementes (PTS) e peso de 100 sementes.

Para a avaliação biométrica das variáveis foram utilizados balança analítica (RADWAG) e paquímetro digital (King tools).

Os dados foram submetidos à análise de variância em software estatístico ASSISTAT versão 7.7, para o teste F a
$5 \%$ de probabilidade, sendo as médias comparadas pelo teste de Tukey (SILVA; AZEVEDO, 2009).

\section{RESULTADOS E DISCUSSÃO}

Foi observado efeito significativo $(\mathrm{p}<0,05)$ para as características morfométricas avaliadas, o Feijão de porco apresentou os maiores índices em todos os parâmetros avaliados, seguido da Mucuna preta e Lablab (Tabela 1), respectivamente.

Tabela 1. Características morfométricas da mucuna preta, feijão de porco e lablab, avaliadas

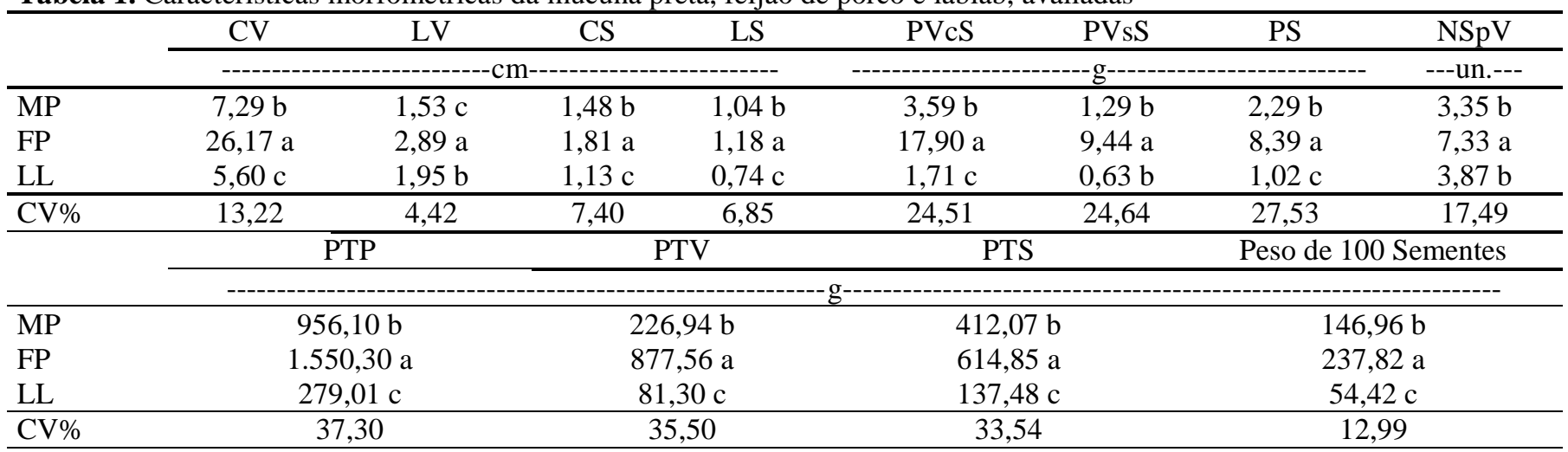

*As médias seguidas pela mesma letra não diferem entre si pelo teste de Tukey a 5\% de probabilidade. **Leguminosa: (MP) Mucuna Preta, (FP) Feijão de Porco e (LL) Lablab, (CV) Comprimento da vagem, (LV) largura da vagem, (CS) comprimento da semente, (LS) largura da semente, (PVcS) peso da vagem com semente, (PVsS) peso da vagem sem semente, (PS) peso da semente, (NSpV) número de semente por vagem, (PTP) peso total da produção, (PTV) peso total das vagens e (PTS) peso total das sementes.

Esse comportamento pode ser atribuído ao próprio aspecto genético do Feijão de porco (Figura 2) quando comparado com as demais leguminosas avaliadas (Figura $1 \mathrm{e}$ 3), assim como, as características de adaptação de cada espécie ao ambiente. Como explicam Rodrigues et al. (2006), onde as diferenças morfométricas estão relacionadas não só a fatores ambientais, mas também às reações da população ao estabelecimento em um novo ambiente, principalmente quando a espécie tem uma ampla distribuição.

Foi observado variações no tamanho e peso das sementes em todas as espécies de leguminosas avaliadas. Segundo Leishaman et al. (2000) e Oliveira et al. (2009), essas variações existem nessas plantas e não são provocadas por diferenças genéticas, mas decorrentes dos efeitos do ambiente durante o seu desenvolvimento. Contudo essas variações podem interferir na sua qualidade fisiológica, a qual ainda é muito pouco pesquisada nestas leguminosas.

Figura 1. Aspectos morfológicos do fruto e da semente de Mucuna aterrima, A - Comprimento da vagem, B - Largura da vagem, $\mathrm{C}$ - Comprimento da semente, D - Largura da semente, E - Peso da vagem e F - Peso de semente.

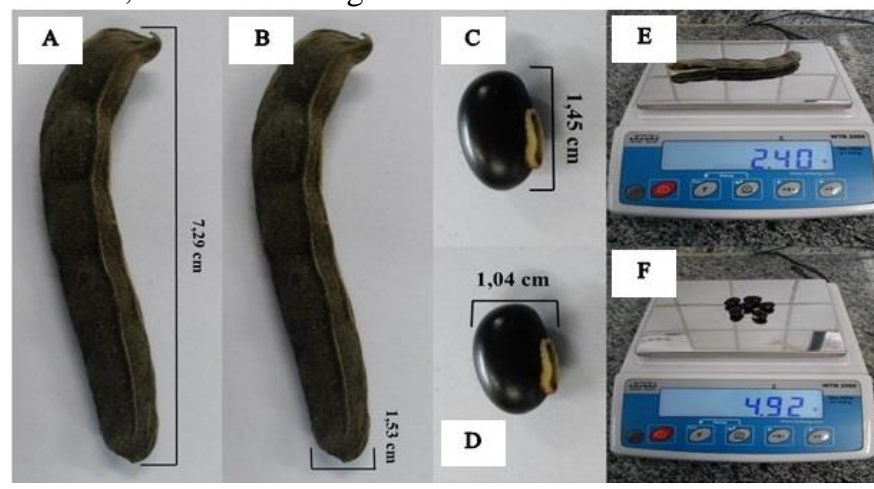

Figura 2. Aspectos morfológicos do fruto e da semente de Canavalia ensiformis D. C. A - Comprimento da vagem, B Largura da vagem, C - Comprimento da semente, D Largura da semente, E - Peso de semente e F - Peso da vagem.

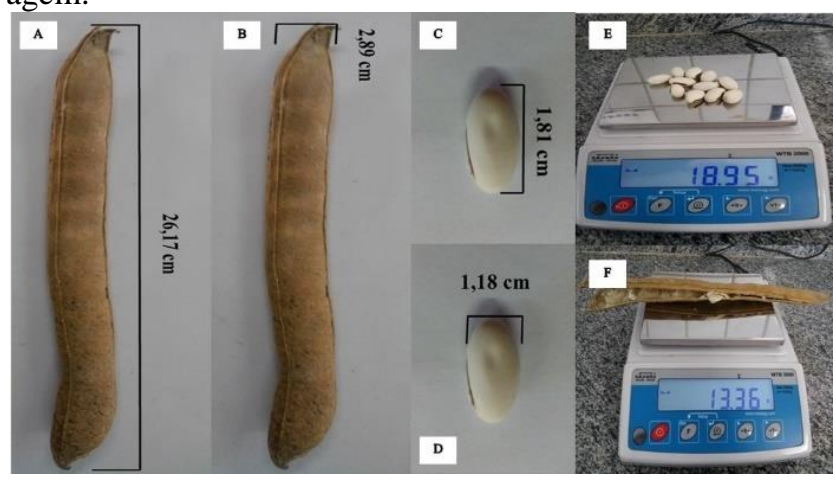

Figura 3. Aspectos morfológicos do fruto e da semente de Dorichos lablab L., A - Comprimento da vagem, B - Largura da vagem, C - Comprimento da semente, D - Largura da semente, E - Peso de semente e F - Peso da vagem.

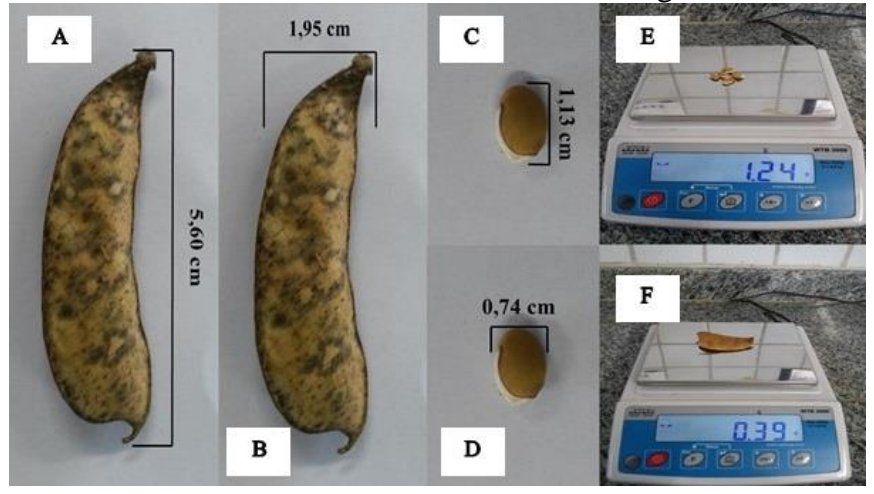


Em relação à característica número de semente por vagem o Feijão de porco apresentou resultados superiores aos demais, contudo de acordo com Andrade et al. (1998), essa é uma característica verietal e que não é muito influenciada pelo ambiente.

A caracterização morfométricas de sementes fornece subsídios que facilitam o reconhecimento destas espécies. Além de gerar informações que servirão como base para determinar o potencial reprodutivo de certas espécies e sua respectiva viabilidade quanto a sobrevivência das plântulas. Segundo White et al. (1992), a classificação das sementes baseadas em suas características morfológicas, pode ser utilizada como estratégia de produção, pois quanto maior a semente melhor será sua germinação e vigor das plântulas conseguintes. Para Ferreira e Borghetti (2008), sementes consideravelmente maiores são associadas ao maior vigor de plântulas, fotossinteticamente ativas, o que favorecerá sua sobrevivência em ambientes com baixa iluminação.

Não foi observado efeito significativo $(\mathrm{p}<0,05)$ para as características morfométricas avaliadas nos diferentes espaçamentos.

Fernandes et al. (1999) e Amabile et al. (2000) relacionam que arranjos populacionais e desempenho de leguminosas anuais têm evidenciado a importância da densidade do plantio para o estabelecimento e para a produção de matéria seca de diversos adubos verdes.

Considerando-se o fato de haver pouca disponibilidade de sementes de leguminosas no comércio é importante que o agricultor tenha a sua própria produção. Para tanto, deve ser reservada parte da área para multiplicação de sementes (LOPES, 2000). De acordo com Alves et al. (2005), a maturidade fisiológica das sementes é importante para o conhecimento da reprodução das espécies vegetais, possibilitando a previsão da época adequada de colheita.

A produção de sementes de leguminosa poderá ser uma estratégia para aumentar a renda dos agricultores familiares no semiárido paraibano, assim como, a melhoria das características de solo. Machado (2003) destaca que ainda a soberania alimentar do país começa com a independência do produtor em dispor, ou de suas próprias sementes, ou de poder adquiri-las facilmente, saindo, assim, da dependência das sementes vendidas pelas multinacionais.

$\mathrm{Na}$ maioria das pesquisas com leguminosas observa-se expressiva variabilidade de comportamento das espécies vegetais em função do ambiente, seja por meio dos efeitos do clima, principalmente da temperatura e precipitação pluviométrica, seja por meio do fotoperíodo e dos atributos químicos, físico-hídricos e biológicos dos solos, resultando em oscilações significativas na acumulação de massa pela parte aérea das plantas (SPERA; CARVALHO, 2006). Assim, trabalhos que visem avaliar as características morfométricas das sementes das leguminosas devem continuar sendo elaborados.

\section{CONCLUSÕES}

Os espaçamentos não influenciam as características morfométricas das sementes de leguminosas.

\section{AGRADECIMENTOS}

Agradecimento a Universidade Federal da Paraíba, Centro de Ciências Humanas, Sociais e Agrárias, Conselho Nacional de Pesquisa - CNPq.

\section{REFERÊNCIAS}

ANDRADE, M. J. B.; DINIZ, A. R.; CARVALHO, J. G.; LIMA, S. F. Resposta da cultura do feijoeiro à aplicação foliar de molibdênio e às adubações nitrogenadas de plantio e cobertura. Ciências e Agrotecnologia. v. 22, p. 499-508, 1998.

AMABILE, R. F.; FANCELli, A. L.; CARVALHO, A. M. Comportamento de espécies de adubos verdes em diferentes épocas de semeadura e espaçamentos na região dos cerrados. Pesquisa Agropecuária Brasileira, v. 35, p. 47-54, 2000.

ALVES, E. U.; SADER, A.; ALCÂNATAR BRUNO, R. L.; ALVES, A. U. Maturação fisiológica de sementes de sabiá (Mimosa caesalpiniifolia Benth.). Revista Brasileira de Sementes, v. 27, n. 1, p. 1-8, 2005.

BARRETO, A. C.; ANJOS, J. L.; FERNANDES, M. F.; SOBRAL, L. F. Uso de leguminosas. In: Melo, M. B.; Silva, L. M. S. Aspectos técnicos dos citros em Sergipe. Aracaju: Embrapa Tabuleiros Costeiros. 82 p. 2006.

BEVILAQUA, G. A. P.; ANTUNES, I. F. Agricultores guardiões de sementes e o desenvolvimento in situ de cultivares crioulas. Artigo de divulgação na mídia, Embrapa, 4 p., 2008.

BUENO, J. R.; SAKAI, R. H.; NEGRINI, A. C.; AMBROSANO, E. J.; ROSSI, F. Caracterização química e produtividade de biomassa de quatro espécies de mucuna. Revista Brasileira de Agroecologia, v. 2, n. 2, p. 901-904. 2007.

FERNANDES, M. F.; BARRETO, A. C.; EMÍDIO FILHO, J. Fitomassa de adubos verdes e controle de plantas daninhas em diferentes densidades populacionais de leguminosas. Pesquisa Agropecuária Brasileira, v. 34, p. 1593-160. 1999.

FERREIRA, A. G.; BORGHETTI, F. Germinação: do básico ao aplicado. Porto Alegre: Artmed, 321 p., 2008.

FORMENTINI, E. A.; LÓSS, F. R.; BAYERL, M. P.; LOVATI, R. D.; BAPTISTI, E. Cartilha sobre adubação verde e compostagem. Vitória: Incaper, 27 p., 2008.

GUTIÉRREZ, M. M. Sementes Crioulas: Um Olhar A Partir da Colômbia. In: Carvalho, H. M., (ORG) Sementes: patrimônio do povo a serviço da humanidade. $1^{\mathrm{a}}$ ed. São Paulo: Expressão Popular, p. 261-277, 2003.

HOWIESON, J. G.; YATES, R. J.; FOSTER, K. J.; REAL, D.; BESIER, R. B. Prospects for the future use of legumes. In DILWORTH, M. J.; JAMES, E. K.; SPRENT, J. I.; NEWTON, W. E. (Eds.), Nitrogen-fixing leguminous symbioses, The Netherlands: Springer, p. 363-394, 2008.

LEISHAMAN, M. R.; WRIGHT, I. J.; MOLES, A. T.; WESTOBY, M. The evolutionary ecology of seed size. In: Fenner, M. (Ed.). Seeds: the ecology of regeneration in plant communities. Wallingford: CAB International, p. 31-57, 2000 . 
LIMA, J. R.; SANTOS, N. D.; TOZZI, A. M. G. A.; MANSANO, V. F. Using legumes as indicators in the seasonally dry vegetation types in South America. Ecological Indicators, v. 73, p. 708-715, 2017.

LOPES, O. M. N. Feijão de porco leguminosa para controle de mato e adubação verde do solo. Altamira-PA: Embrapa Amazônica Oriental, p. 4, 2000. Disponível em: <http://ainfo.cnptia.embrapa.br/digital/bitstream/item/38454/1 /FeijaoPorcoLeguminosa.pdf>. Acesso em: 16 abr. 2017.

MACHADO, J. Internet, Ativismo Político e Controles Governamentais, paper apresentado no XI Congresso da Sociedade Brasileira de Sociologia, Campinas-SP, Brasil, 2003.

OLIVEIRA, A. B.; MEDEIROS-FILHO, S.; BEZERRA, A. M. E.; BRUNO, R. L. A. Emergência de plântulas de Copernicia hospita Martius em função do tamanho da semente, do substrato e do ambiente. Revista Brasileira de Sementes, Brasília, v. 31, n. 1, p. 281-287, 2009.

PETERSEN, P.; SILVEIRA, L.; DIAS, E.; CURADO, F.; SANTOS, A. Sementes ou grãos? Lutas para desconstrução de uma falsa dicotomia. Agriculturas, v. 10, n. 1, p. 36-45, 2013.

RODRIGUES, J. E. L. F.; ALVES, R. N. B.; LOPES, O. M N.; TEIXEIRA, R. N. G.; ROSA, E. S. A importância do feijão de porco (Canavalia ensiformis D. C.) como cultura intercalar em rotação com milho e feijão caupi em cultivo de coqueirais no município de Ponta-de-Pedras/Marajó-PA. Belém: Embrapa Amazônia, (Comunicado Técnico n 96), 4 p., 2004.

RODRIGUES, A. C. C.; OSUMA, J. T. A.; QUEIROZ, S. R. O. D.; RIOS, A. P. S. Biometria de frutos e sementes e grau de umidade de sementes de angico (Anadenanthera colubrina
(Vell.) Brenan var. cebil (Griseb.) Altschul) procedentes de duas áreas distintas. Revista Científica Eletrônica de Engenharia Florestal, v. 4, n. 8, p. 1-15, 2006.

SANTOS, C. M.; GONÇALVES, E. R.; ENDRES, L.; GOMES, T. C. A; JADOSKI, C. J.; NASCIMENTO, L. A.; SANTOS, E. D. Atividade fotossintética em alface (Lactuca sativa L.) submetidas a diferentes compostagens de resíduos agroindustriais. Pesquisa Aplicada e Agrotecnologia, Paraná PR, v. 3, n. 3, p. 95-102, 2010.

SILVA, F. A. S.; AZEVEDO, C. A. V. 2009. Principal components analysis in the software Assistat-Statistical Attendance. In: World Congress On Computers In Agriculture, Reno. Proceedings... Reno, American Society of Agricultural and Biological Engineers, 1 CD-ROM. p. 7, 2009.

SOUZA, L. A. G. Leguminosas para adubação verde na terra firme e na várzea da Amazônia central. Um estudo em pequenas propriedades rurais em Manacapuru. INPA/CPCA: Coordenação de Pesquisa em Ciências e Agronômicas, Manaus - AM, v. 1, n. 40, p. 08-09, 2012.

SPERA, S. T.; CARVALHO, A. M. Solos do Bioma Cerrado: propriedades químicas e físico hídricas sob uso e manejo de adubos verdes. In: Amabile, R. F.; Carvalho, A. M. (Org.). Cerrado: adubação verde. Planaltina, DF: Embrapa Cerrados, p. 41-70, 2006.

TADESCO, V. Utilização de Mucuna preta como alternativa ao uso do fogo. Ascom-RO. 2009. Disponível em: http://www.ecodebate.com.br. Acesso em: 15 de jun. de 2017.

WHITE, J. W.; SINGH, S. P.; PINO, C.; BUDDENHAGEN, I. Effects of seed size and photoperiod response on crop growth and yield of common bean. Field Crops Research, v. 28, n. 4, p. 295-307, 1992. 